\title{
Research on Passenger Travel Mode Choices of Self-driving Travel
}

\author{
Xinchao Liang ${ }^{a}$ and Yu Zhao ${ }^{b}$ \\ School of Traffic and Transportation, Beijing Jiaotong University, Beijing, 100044, China \\ a16120763@bjtu.edu.cn, byuzhao@bjtu.edu.cn
}

Keywords: Self-driving travel modes; Selective model; Car rental.

\begin{abstract}
With the development of Chinese automobile industry and the continuous improvement of the transport facilities, the concept of self-driving travel is no longer confined to the characteristics of close range or short time. This paper studies the current situation of self-driving travel at home and abroad. According to the different characteristics, self-driving travel modes could be divided into three forms: traditional self-driving travel, self-driving car transportation and car rental in the tourist destination. In this paper, the influence factors of travel mode choices are divided into subjective, objective and other factors. The paper tried to establish a model for selecting travel mode, analyzed the characteristics of the three kinds of self-driving travel modes and provided more rational references for the travelers when they want to go on a self-driving travel.
\end{abstract}

\section{Research Significance and Background}

In recent years, with the rapid development of the economy, the holding quantity of private car increase rapidly and people's attention to self-driving travel is higher and higher. The continuous improvement of tourist information, transportation services and the paid vacation system makes more and more people have conditions and is willing to try a self-driving travel [1].

According to the statistics of the Traffic Management Bureau of Ministry of public security, by the end of 2016, the national motor vehicle reaches a total of 290 million cars and per hundred households have 36 cars. Motor vehicle drivers reaches 360 million, including more than 310 million car drivers [2].

According to the National Tourism Administration issued data: the number of self-driving travel increased to 2340 million in China in 2015, accounting for $58.5 \%$ of the number of tourism [2]. Selfdriving travel has shown its powerful potential in the Chinese market, it has become an important way for people to travel over the past decade. The self-driving travel groups have become the main force in the tourism market, so the study of self-driving tour is of great significance.

\section{The Current Situation of Self-driving Travel}

\subsection{Travel Mode Classification.}

According to the different classification standard, self-driving travel can be divided into different categories: according to the organization form, it is divided into individual, individual team and selfdriving team; according to the travel distance, it is divided into short, middle and long distance tour [1]. In this paper, according to the different characteristics, it can be divided into three forms: (1) Traditional self-driving travel. The way is a continuous process of employing private cars or vehicles as the main transportation and taking the experience and leisure as the main purpose. (2) Self-driving car transportation. The passengers can transport their cars by train to tourist destinations and take public transportation to go to the destinations. Then they can drive the car to complete the driving process. (3) Car rental in the tourist destination. It mainly refers to passengers take other transportation to the tourist destinations, then they can rent local cars to tour.

\subsection{Self-driving Modes and Space.}

From the point of view of the temporal and spatial distribution of self- driving travel, we mainly can divide into three modes: spot tourism, linear tourism and base tourism. From the scope of the space, the $100-300 \mathrm{~km}$ accounted for about $70 \%$ and the $300-500 \mathrm{~km}$ accounted for about $20 \%$. This 
result is related to the holiday of the tourists, which means that the distance is limited in a short holiday. Therefore, with the gradually prosperity of the self-driving travel market, the scope of selfdriving travel needs to expand urgently.

\section{Building the Decision-making Model}

Self-driving travel is a kind of tourism consumption behavior. The travel decision is influenced by many factors, analyzing these factors is the basis of analyzing the consumer behavior. These factors are divided into subjective, objective and other factors (Fig.1). Subjective factors include purpose, security, income, age, gender; objective factors include vacation time limit, travel distance, transportation cost, transportation facilities; other factors include the weather condition, the number of trips, travel information collection, service quality, destination condition [3, 4].

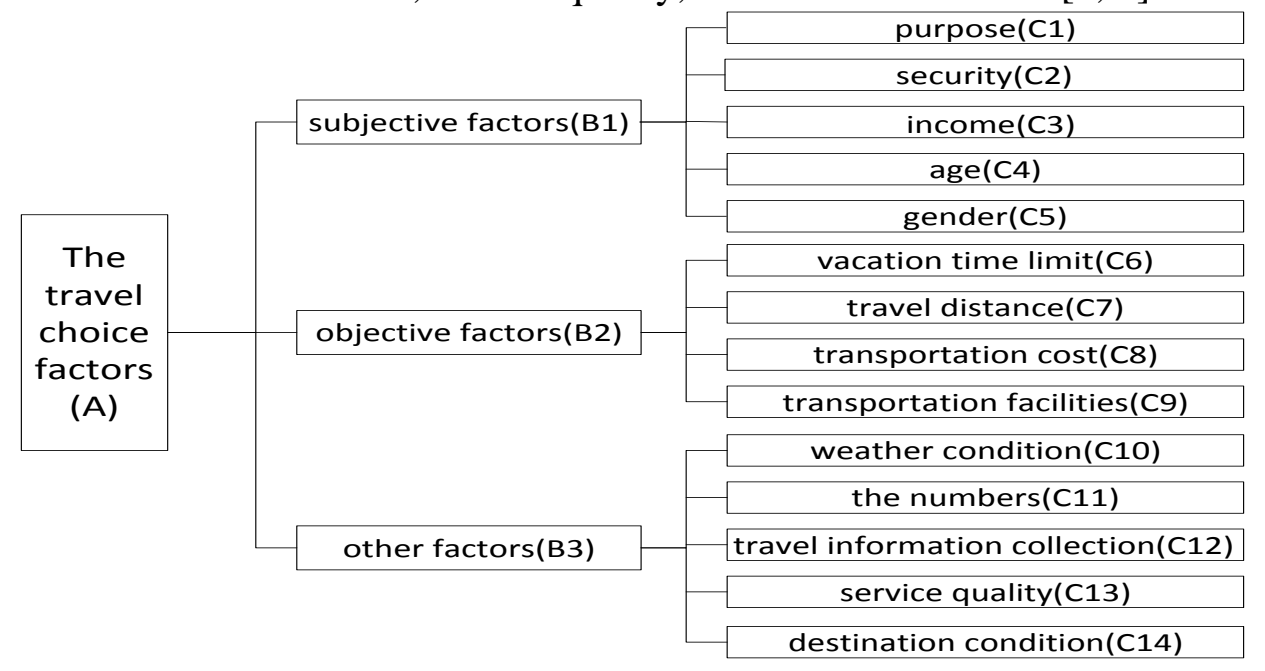

Fig. 1 The hierarchical structure of the passenger travel mode choice model

These factors have conjunct restrictive function on the self-driving decision. In certain situations, if some factors above change, the transportation decisions will change. Based on this, we can build the interactional three-dimensional model (Fig.2) [4]. It conforms to the rule of resulting forces in physics, the resultant values collectively play roles on the final decision. The formulas show as (1), (2).

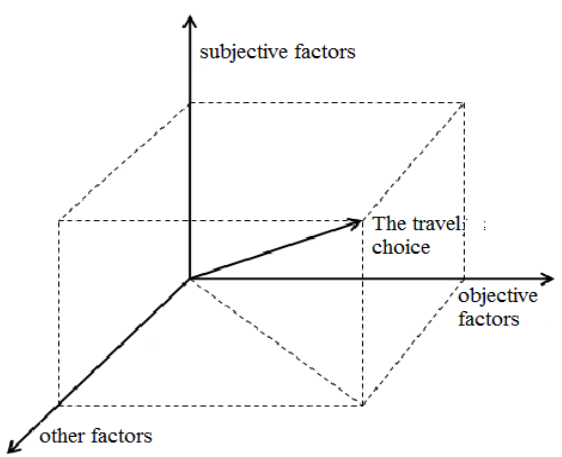

Fig 2. Transportation decision model

For example, when the function of vacation time limit is larger, the passengers may be less consider the subjective factors and other factors. It will be reflected in the final travel decision: to abandon the slower traditional self-driving travel and choose the faster car rental way to travel.

$$
\begin{gathered}
\mathrm{F}_{i}=\sqrt{\sum_{j=1}^{3} \mathrm{x}_{i j}^{2}} \\
x_{i j}=\sum w * m
\end{gathered}
$$

$F_{i}$-the selective parameter value of the " $i$ " mode of travel; $x_{i j}$-the index value of the " $j$ " factor from the "C" layer of the " $i$ " mode of travel; $w$-the weight of the " $j$ " factor from the " $C$ " layer of the " $i$ " mode of travel; $m$-the attribute value of the " $j$ " factor from the " $C$ " layer of the " $i$ " mode of travel. 


\section{The Instance Analysis on Beijing to Xian Channel}

March 2017 in Beijing, Xian and other places, by linking the passenger transport channels in the questionnaire survey (200) to collect the relevant index of the raw data. Then collected the attribute values in the questionnaires and their arithmetic average is the ultimate attribute values of all the factors (Table 1).

Table 1. The attribute values of three modes of transportation

\begin{tabular}{|c|c|c|c|c|c|c|c|c|c|c|c|c|c|}
\hline $\begin{array}{c}\text { The Modes of } \\
\text { Transportation }\end{array}$ & $\mathrm{C} 1$ & $\mathrm{C} 2$ & $\mathrm{C} 3$ & $\mathrm{C} 4$ & $\mathrm{C} 5$ & $\mathrm{C} 6$ & $\mathrm{C} 7$ & $\mathrm{C} 8$ & $\mathrm{C} 9$ & $\mathrm{C} 10$ & $\mathrm{C} 11$ & $\mathrm{C} 12$ & $\mathrm{C} 13$ \\
\hline $\begin{array}{c}\text { Traditional Self- } \\
\text { driving Travel }\end{array}$ & 4 & 3 & 3 & 2 & 1 & 3 & 1 & 3 & 4 & 4 & 3 & 3 & 4 \\
\hline $\begin{array}{c}\text { Self-driving Car } \\
\text { Transportation }\end{array}$ & 2 & 3 & 4 & 5 & 5 & 4 & 1 & 5 & 3 & 5 & 4 & 2 & 3 \\
\hline $\begin{array}{c}\text { Car Rental in the } \\
\text { Destination }\end{array}$ & 2 & 2 & 4 & 5 & 4 & 3 & 3 & 4 & 3 & 5 & 4 & 2 & 4 \\
\hline
\end{tabular}

In this paper it takes expert scoring method in handling the factors of the " $\mathrm{C}$ " layer. The paper set up all the factors' value range from 1 to 5. Then using the AHP (analytic hierarchy process) to make a normalized processing in every specific parameters to get weight of factors. As the formula (2) multiplying the attribute values and the weight is regarded as the index values of the " $\mathrm{B}$ " layer three factors, then dragging the index values into formula (1) gains the selective parameter values. The calculation result is shown in Table 2:

Table 2. The final values of the channel (from Beijing to Xian)

\begin{tabular}{|c|c|c|}
\hline The Mode of Transportation & Travel Distance & Selective Parameter Values \\
\hline Traditional Self-driving Travel & $1100 \mathrm{~km}$ & 2.5487 \\
\cline { 1 - 1 } Self-driving Car Transportation & (from Beijing to & 2.2472 \\
\cline { 1 - 1 } Car Rental in the Tourist Destination & Xian) & 1.9649 \\
\hline
\end{tabular}

When the channel changes to go from Harbin to Hainan, the final values of three mode of transportation in Table 3:

Table 3. The final values of the channel (from Harbin to Hainan)

\begin{tabular}{|c|c|c|}
\hline The Mode of Transportation & Travel Distance & Selective Parameter Values \\
\hline Traditional Self-driving Travel & & $2700 \mathrm{~km}$ \\
\cline { 1 - 1 } Self-driving Car Transportation & (from Harbin to & 1.6256 \\
\cline { 1 - 1 } Car Rental in the Tourist Destination & Hainan) & 2.4961 \\
& & 2.2396 \\
\hline
\end{tabular}

\section{Conclusion}

On the premise of self-driving car transportation's operation, through the result could obtain the traditional self-driving travel is much better than the other two ways and self-driving car transportation has more advantages than car rental under certain conditions. Comparing the two tables, when travel distance is longer, the values that passengers chosen the traditional way reduced obviously, more and more people select car rental and self-driving car transportation.

This model can provide the travel reference for passengers. The three kinds of modes have their own advantages and disadvantages, comparing with the traditional way, the latter two ways avoid the midway tiredness. Car rental has many advantages. Because the vehicles come from the local rental market, it saves the cost for transporting vehicles, slows the traffic congestion problem of destination city and so on. Selecting the travel mode rationally is the trend to the development of self-driving trip in the future. A variety of travel modes are promoting the development of tourism, at the same time the government should provide more low cost and resources cost schemes. Overall with the constant improvement of self-driving travel and related products, the three ways can meet the demand of different groups and have wide development prospects. 


\section{References}

[1] Ting Ting Ye. Study on consuming behavior of self-driving tourists in Hangzhou and the marketing strategy from the perspective of tourism destination (Master's thesis, Zhejiang Gong Shang University, China 2014)

[2] Information on: http://www.autohome.com.cn

[3] Xue Mei Zhang. The analysis of self-driving tourist traffic behavior (Doctoral dissertation, Southwest Jiaotong University, China 2011)

[4] Peng Zhang, Ni Yang Yin, Jian Xi Feng. The analysis of diversified self-driving transportation based on the travel decision-making model. Proceedings of the 2015 annual meeting of urban planning in China. Guiyang, China Guizhou, 2015. 